\title{
Southern Blotting
}

National Cancer Institute

\section{Source}

National Cancer Institute. Southern Blotting. NCI Thesaurus. Code C16356.

A technique for the detection of specific DNA fragments that have been separated by polyacrylamide-gel electrophoresis, transferred to a nitrocellulose or other type of paper or nylon membrane, and detected by hybridization and visualization with a labeled probe. 